\title{
Refinement of strategies for the development of a human cytomegalovirus dense body vaccine
}

\author{
Véronique Mersseman • Verena Böhm • \\ Rafaela Holtappels · Petra Deegen · Uwe Wolfrum • \\ Bodo Plachter · Sabine Reyda
}

Received: 1 February 2008 / Published online: 5 March 2008

(C) Springer-Verlag 2008

\begin{abstract}
Development of a vaccine against human cytomegalovirus (HCMV) infection has been identified as a high priority goal in biomedical research, yet no vaccine has been licensed until now. Recombinant subviral dense bodies (recDB) are a promising basis for the establishment of such a vaccine. In this article, strategies for the generation of recDB, based on recombination-mediated genetic engineering of the $230 \mathrm{~kb}$ HCMV DNA genome in E. coli are outlined. Analysis of viral mutants that were constructed in this process provided the proof-of-principle that heterologous antigens can be packaged into recDB and that these particles prime $\mathrm{CD} 8 \mathrm{~T}$ cell responses against the recombinant antigen upon their application to HLA-A2 transgenic mice.
\end{abstract}

Keywords Cytomegalovirus · Vaccine ·

Dense bodies · pp65 - IE1

\section{Introduction}

Infections with human cytomegalovirus (HCMV) continue to be important complications of allogeneic hematopoietic stem cell transplantation (HSCT) [1]. Prenatal HCMV

V. Mersseman · V. Böhm · R. Holtappels · P. Deegen ·

B. Plachter $(\varangle) \cdot$ S. Reyda

Institute for Virology,

Johannes Gutenberg-Universität, Obere Zahlbacher Str. 67,

55101 Mainz, Germany

e-mail: plachter@uni-mainz.de

U. Wolfrum

Institute for Zoology,

Department of Cell and Matrix Biology,

Johannes Gutenberg-Universität, Mainz, Germany infection, in addition, is the leading cause of mental retardation and sensorineural hearing loss in infants in the Western world [2,3], and it may also contribute to morbidity and mortality in newborns in developing countries [4]. Numerous studies have found a strong correlation of immature or impaired immune defence functions with morbidity and mortality second to HCMV infection or reactivation [3]. Cytolytic CD8 T lymphocytes (CTL) have been denominated as key effectors that control viral infection and limit viral reactivation, both in animal models and in clinical studies [5-7]. Consequently, work performed to develop immunotherapeutic or prophylactic intervention strategies against HCMV disease has focused on the enhancement of CD8 and CD4 T cell responses [8-10]. Although the role of $\mathrm{T}$ lymphocytes in the prevention of prenatal HCMV infection and disease remains controversial, there is no doubt that improved reconstitution of CD8 and CD4 T cells is a primary goal of HCMV specific immunotherapy in allogeneic HSCT $[1,11]$.

Success of therapeutic tumor intervention applying allogeneic HSCT is frequently compromised by HCMV reactivation [1]. Depletion of donor-derived lymphocytes to reduce graft-versus-host disease is one risk factor in this context, as antiviral $\mathrm{T}$ cells may be concomitantly depleted [12]. Selective removal of only the alloreactive T cells may be a way to retain antiviral CD8 responses [13, 14]. Transfer of antiviral $T$ cell lines, generated by in vitro stimulation prior to transfusion, has been shown to be another option to reconstitute HCMV immune responses [7-9]. However, logistic limitations and the possible risk of transfer of alloreactive cells together with HCMV specific cells have prevented introduction of such strategies as a clinical routine. $\mathrm{T}$ cell receptor (TCR-) based ex vivo sorting of antiviral CD8 T cells and subsequent adoptive transfer of such cells has been shown to be effective to 
reduce the incidence of cytomegalovirus induced disease in a mouse model $[15,16]$, and it has also been applied in first clinical studies [10]. However, a number of questions regarding the adoptive transfer of HCMV-specific T lymphocytes remain unanswered. Most importantly, the effectiveness of such a procedure to confer lasting protection against HCMV disease after HSCT remains undetermined. Furthermore, it may not be possible to generate HCMV specific T-lymphocytes from HCMV-seronegative donors. One way to improve the potency of the HCMV specific adoptive $T$ cell transfer for immunoprophylaxis is the use of a vaccine for in vivo stimulation of transferred $\mathrm{T}$ cells.

Several vaccine candidates have been introduced, none of which has entered clinical routine, yet [17-20]. We have focused on the development of a vaccine based on subviral dense bodies (DB) [21, 22]. DB enter cells in a way comparable to virions and thereby deliver their proteinaceous content into the cytoplasm. As exemplified for the major component of DB, the pp65 (ppUL83), peptides derived from this tegument protein are efficiently introduced into the MHC class I presentation pathway without requiring de novo protein synthesis [21]. Although pp65 by itself is a prominent target of the CD4 and CD8 T cell responses following natural infection [23-25], other proteins like the non-structural, regulatory IE1-protein (ppUL123) are also targeted by the immune system [26, 27]. Consequently, inclusion of such antigens in a vaccine formulation may be important to induce a broad immune response [15, 26-30]. We have started a project to broaden the antigenic content of DB. Viral mutants that expressed pp65 in fusion with a heterologous polypeptide were generated. Cells infected with these viruses released recombinant DB (recDB) containing the fusion protein, thus proving the feasibility of the approach [31]. This strategy, however, had to be refined with respect to the numbers of recDB released from infected cells. In addition, the methodology of conventional recombination in eukaryotic cells, used for these experiments, may be critical in the development of a vaccine for human application.

The aim of the work described in this article was to define a location within pp65 that allowed fusion with a heterologous polypeptide while retaining efficient release of recDB from HCMV infected cells. For this, we used two different variations of recombination-mediated genetic engineering (recombineering) of bacterial artificial chromosome (BAC) clones of the virus to modify the $230 \mathrm{~kb}$ HCMV genome in E. coli [32-35]. For the sake of this experimental approach, we decided to fuse fragments of the IE1 protein of HCMV, containing HLA-A2 presented peptide determinants, to pp65. For analysis, an antibody tag for an epitope from the c-myc gene was included in some of the recombinants. The respective viral mutants were recon- stituted in human foreskin fibroblasts (HFF) and were subsequently analysed for synthesis and release of recombinant particles by infected HFF.

\section{Materials and methods}

Generation of BAC clones by positive selection using kanamycin resistance $\left(\operatorname{Kan}^{\mathrm{R}}\right)$

The generation of HCMV BACs, using positive selection, was performed according to Lee et al. [34].

\section{Cloning of BAC-SRI}

Primers SR1 and SR2 (Table 1) were used to amplify the IE1 $1_{(288-402)}$ fragment and to introduce a Kozak-ATG as well as the restriction sites for XhoI and BamHI. The PCR fragment was cloned into the $\mathrm{XhoI}$ and BamHI digested vector pCP-o-15-link2 [36], resulting in pCP-IE1 with the FRT$\mathrm{Kan}^{\mathrm{R}}$-FRT cassette upstream of the IE1 fragment. For homologous recombination, the FRT-kanamycin-IE1 region was amplified using primers SR4 and SR5 to insert the IE1 fragment in frame at the N-terminus of pp65 of BAC pHB5 [33].

\section{Cloning of BAC-VRI}

For the construction of the C-terminal pp65 fusion protein, the primer pair SR9/SR10 (Table 1) was used to amplify the FRT-Kan ${ }^{\mathrm{R}}$-FRT cassette from the plasmid template pCP-IE1. The NsiI cleaved PCR-fragment was inserted into NsiI cleaved pBamHIR, a pBluescript based plasmid containing the BamHI R fragment [37] of HCMV with the complete pp65 gene. The resulting plasmid pBamHIR-Kan, with the FRT-Kan ${ }^{\mathrm{R}}$-FRT cassette downstream of pp65 was digested with NheI and ligated with the NheI digested PCR-fragment of the template plasmid pCP-IE1 and primers SR11/SR12. This step adds the IE1 $1_{(288-402)}$-fragment to the C-terminus of pp65. The construct was termed pBamHIR-IE1-Kan. This plasmid was used as template with primers SR13/SR14 to amplify the PCR-fragment for the homologous recombination into pHB5.

\section{Cloning of BAC-EPO, BAC-EP1, BAC-EP2}

To generate pp65-fusion proteins labelled with a myc tag, a PCR product was generated using pBamHIR-Kan as template and the SR16/SR17 primer pair (Table 1) for amplification. The resulting fragment was inserted into a TA cloning vector and the plasmid was termed pK65. Plasmid pK65 contained the $3^{\prime}$ end of UL83 with an 
Table 1 Sequences of the oligonucleotides used for PCR-amplification

\begin{tabular}{|c|c|c|}
\hline Name & Used to construct & Sequence \\
\hline SR1 & pCP-IE1 & GAGACTCGAGCCACCATGAAGGTCACTAGTGACGCTTGTATG \\
\hline SR2 & pCP-IE1 & GAGA GGA TCC TGA CAC CAG AGA ATC AGA GGA GC \\
\hline SR4 & RV-SR1 & $\begin{array}{l}\text { CCCAGTACGGATATCATTTCGGGACAACGGCGCCAGCGCG } \\
\text { ACTCCATTGACACCAGAGAATCAGAGGAG }\end{array}$ \\
\hline SR5 & RV-SR1 & $\begin{array}{l}\text { CAGAGGGCGCGCCGCTCAGTCGCCTACACCCGTACGCGCAGGCA } \\
\text { GCTAATTAAGGCGCGCCGGTACC }\end{array}$ \\
\hline SR9 & pBamHIR-Kan & $\begin{array}{l}\text { GAGAATGCATCGCCTCGACGCCCAAAAAGCACCGAGGTGC } \\
\text { TAGCTAATTAAGGCGCGCCGGTAC }\end{array}$ \\
\hline SR10 & pBamHIR-Kan & GAGAATGCATCATGGTGGCTCGAGAAACG \\
\hline SR11 & pBamHIR-IE1-Kan & GAGAGCTAGCAAGGTCACTAGTGACGCTTGTATG \\
\hline SR12 & pBamHIR-IE1-Kan & GAGAGCTAGCTCATGACACCAGAGAATCAGAGGAG \\
\hline SR13 & RV-VR1 & CCGAATTGGAAGGCGTATGG \\
\hline SR14 & RV-VR1 & TGTTCCGCTTCCTTTAGCAG \\
\hline SR16 & pK65 & $\begin{array}{l}\text { GCCTTGCCCGGGCCATGCATCGCCTCGACGCCCAAAAAGC } \\
\text { ACCGAG }\end{array}$ \\
\hline SR17 & pK65 & $\begin{array}{l}\text { GGACGTGGGTTTTTATAGAGTCGTCCTAAGCGCGTGCGGCGGGTGGC } \\
\text { CATGGTGGCTCGAGAAACGCAGCT }\end{array}$ \\
\hline SR22 & pK65-1 for pBAC-EP1 cloning & GAGAGCTAGCACTAGTGACGCTTGTATGATG \\
\hline SR23 & pK65-1 for pBAC-EP1 cloning & $\begin{array}{l}\text { GAGAGCTAGCTCACAGATCCTCTTCTGAGATGAGTTTTTGT } \\
\text { TCAGGCCGCTTGGCCAGCATC }\end{array}$ \\
\hline SR24 & pK65-2 for pBAC-EP2 cloning & GAGAGCTAGCACTAGTGACGCTTGTATGATG \\
\hline SR25 & pK65-2 for pBAC-EP2 cloning & $\begin{array}{l}\text { GAGAGCTAGCTCACAGATCCTCTTCTGAGATGAGT } \\
\text { TTTTGTTCACAGAACTCACTTAAGAGAGAG }\end{array}$ \\
\hline SR26 & pK65-0 for pBAC-EP0 cloning & CTAGCGAACAAAAACTCATCTCAGAAGAGGATCTGTGAG \\
\hline SR27 & pK65-0 for pBAC-EP0 cloning & CTAGCTCACAGATCCTCTTCTGAGATGAGTTTTTGTTCG \\
\hline
\end{tabular}

adjacent FRT-Kan ${ }^{\mathrm{R}}$-FRT cassette. In order to construct the pK65-0 plasmid, the complementary oligonucleotides SR26 and SR27, which carried the nucleic acid sequence of a c-myc tag and a stop codon flanked by NheI restriction sites, were annealed. This annealing product was then digested with NheI and sub-cloned into a NheI digested pK65 plasmid.

The sequences coding for the IE1 peptides IE1 $1_{(288-309)}$ and IE $1_{(309-328)}$ were amplified by PCR using the pCP-IE1 plasmid with the respective forward primers (SR24, SR22) containing a NheI restriction site, and with the respective reverse primers (SR25, SR23), containing sequences of a c-myc tag, a stop codon and a NheI restriction site. The pK65-1 plasmid, carrying the coding sequence for the IE $1_{(288-309)}$ peptide, and the pK65-2 plasmid, containing the coding sequence for the $\mathrm{IE} 1_{(309-328)}$ peptide, were obtained by sub-cloning the different NheI digested PCR products into the NheI digested pK65 plasmid. To fuse the different IE1 fragments at the C-terminus of pp65 into the HCMV BAC, PCR fragments were generated using primers SR16/SR17 and plasmid pK65-1 resulting in BAC-EP1, or plasmid pK65-2 for BAC-EP2, or plasmid pK65-0 for BAC-EP0. The correct nucleotide sequences of all plasmids and BACs were verified by sequencing the modified regions. All used primers are listed in Table 1.

\section{Results}

Construction of recombinant viruses expressing

$\mathrm{N}$ - and C-terminal fusion proteins of pp65

In a first attempt to optimise the generation of recDB, different portions of the IE1 protein carrying one or more immunodominant HLA-A2 presented determinants were fused to the $\mathrm{N}$ - and $\mathrm{C}$ - terminus of pp65 (Fig. 1a-c). Using this technology, several recombinant viruses were established (Fig. 1d). The C-terminal part of pp65 was chosen to fuse either the IE $1_{\mathrm{TMY}}$ determinant $\left(\mathrm{IE} 1_{(297-304)}\right.$, TMYGGISLL) [38] or the IE1 $1_{\mathrm{VLE}}$ determinant (IE1 $1_{(316-324)}$, VLEETSVML) [39, 40]. The single nonamer peptides were extended by flanking amino acids $\left(I E 1_{(288-309)}\right.$ and IE $\left.1_{(309-328)}\right)$ to ensure proper proteolytic processing. Furthermore, the IE1 peptides were labelled with a c-myc epitope tag to facilitate analysis (recombinants RV-EP1 and RV-EP2). A pp65 fusion protein, containing the minimal myc-tag was also generated for control (RV-EP0). Lastly, a 
a

b

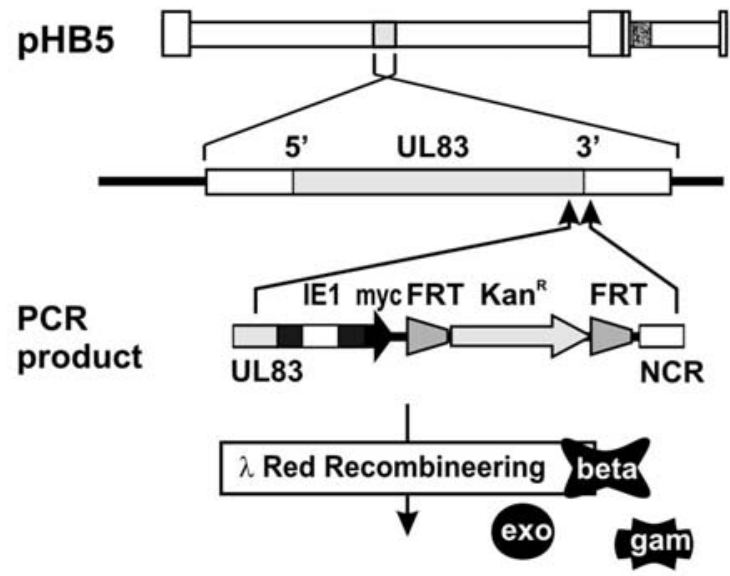

\section{BAC-EP1-Kan}

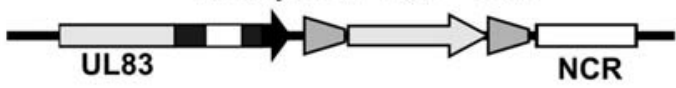

C

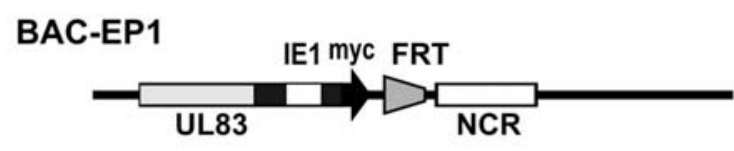

d
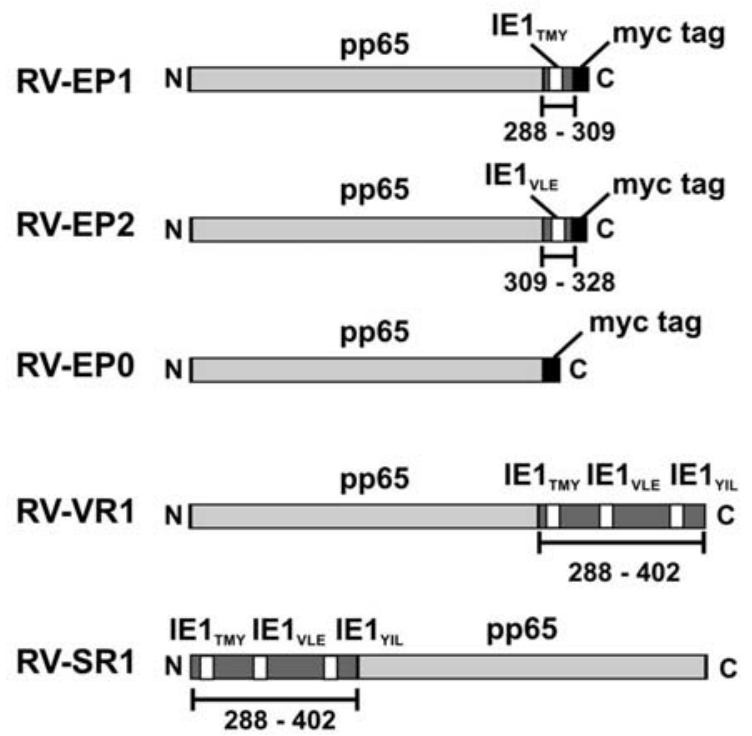

longer IE1 polypeptide (IE1 $1_{(288-402)}$ ) was selected, containing both $\mathrm{IE} 1_{\mathrm{TMY}}$ and $\mathrm{IE} 1_{\mathrm{VLE}}$ as well as the sub-dominant determinant $I E 1_{\text {YIL }}\left(\operatorname{IE} 1_{(354-363)}\right.$, YILGADPLRV) [41], all presented by HLA-A2 (RV-VR1). The same fragment was also fused to the very N-terminus of pp65 [42] (Fig. 1d; RV-SR1). After FLP-mediated excision of $\mathrm{Kan}^{\mathrm{R}}$ from each $\mathrm{BAC}$, the correct insertion was verified by nucleotide
Fig. 1 Genetic modification of HCMV BACs using positive selection by $\mathrm{Kan}^{\mathrm{R}}$. As an example, the cloning procedure for BAC-EP1 is shown. For $\lambda$-Red-recombineering, E. coli strain EL250 was used. These bacteria carry the $\lambda$-Red genes exo, beta and gam under heatinducible promoter control and an arabinose inducible FLP-recombinase gene, both as chromosomal integrates [34]. a Structure of the PCR-product used for homologous recombination into the $\mathrm{C}$-terminus of the pp65 gene of the HCMV BAC pHB5 by recombineering. b Structure of the intermediate BAC clone BAC-EP1-Kan. Bacteria harbouring this BAC were induced for FLP expression by the addition of arabinose. c Structure of the final construct BAC-EP1 after excision of FRT-Kan ${ }^{\mathrm{R}}$. This BAC served as the basis for the reconstitution of RVEP1.d structure of the pp65 fusion proteins expressed from the different recombinant viruses. The portions of IE1 are indicated by dark grey boxes and are represented with respect to the IE1 protein sequence below each bar. The different HLA-A2 presented peptides from IE1 are shown as white boxes. The pp65 sequence is represented by light grey bars, the myc tag sequence by black boxes. NCR non-coding region of the UL83 gene; FLP flip recombinase

sequencing and the recombinant viruses were reconstituted in HFF.

Expression and packaging of the $\mathrm{N}$ - and $\mathrm{C}$-terminal pp65-IE1 fusion proteins in infected cells

The expression of the fusion proteins in infected HFF was verified by immunoblot analysis and indirect immunofluorescence. No expression of the fusion protein from RV-SR1 could be detected in crude lysates from infected cells (data not shown). This virus was thus excluded from further analysis. In contrast, all C-terminal fusion proteins were expressed in HFF infected with the respective mutant (Fig. 2a). No significant differences in the steady-state levels of these proteins became apparent.

To analyse the subcellular localisation of the fusion proteins, indirect immunofluorescence analyses were performed (Fig. 2b). Cells infected with RV-HB5 showed the well-established nuclear localisation of pp65 at 2 days p.i. and the cytoplasmic shift at 4 d.p.i.. In cells infected with RV-VR1, pp65 was only vaguely detectable at 2 days p.i., and was localized in the cytoplasm at 4 days p.i.. In cells infected with the RV-EP0 and RV-EP1, the fusion protein was translocated from the nucleus to the cytoplasm during later stages of infection. This was comparable to the parental strain. In contrast, in cells infected with RV-EP2, the fusion protein remained mainly in the nucleus. To test whether the fusion proteins of the different viral mutants were incorporated into extracellular progeny viral particles, the different particle fractions were separated by glyceroltartrate gradient centrifugation of culture supernatants from infected cells [43] (data not shown). The gradient obtained from RV-HB5 infected cells showed the typical banding pattern of HCMV viral particles, consisting of NIEPs, virions and DB. In the gradients from RV-VR1, RV-EP1 and $\mathrm{RV}$-EP2 infected cells, the NIEPs and virion bands, but no 
a

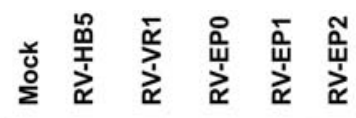

anti-pp65

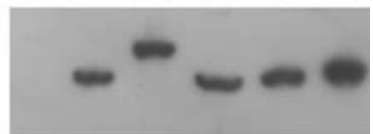

anti-gB

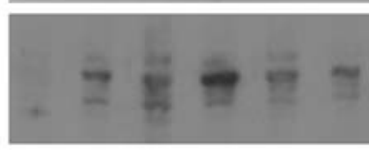

b

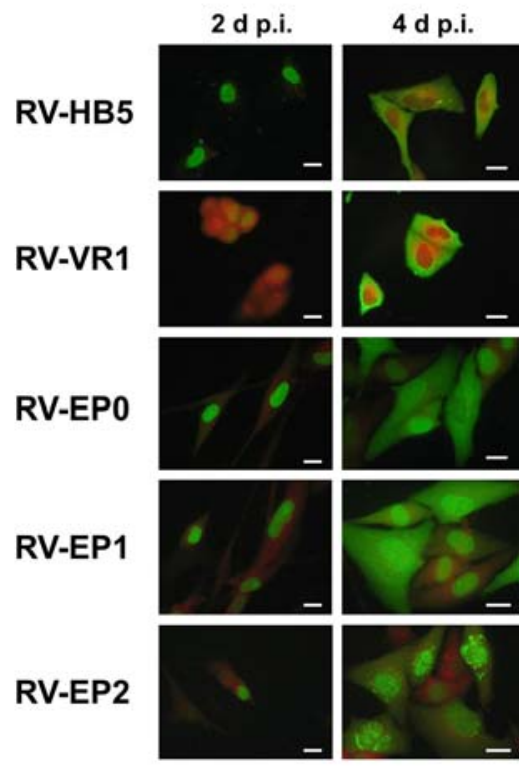

c

anti-pp65

anti-gB
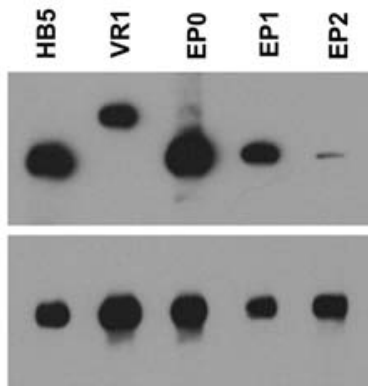

Fig. 2 Analysis of pp65 fusion protein expression, subcellular distribution in infected HFF, and content in the extracellular NIEPs fractions. a Immunoblot analysis of pp65 and pp65 fusion protein expression in infected HFF. Cell lysates from infected cells were collected at 4 d.p.i. and were analysed by immunoblotting. The amount of protein loaded on each lane was normalized against HCMV gB ( $m A b$ 27-287). The fusion proteins were detected with an antibody against pp65 (mAb 65-33). b Immunofluorescence analysis of the subcellular distribution of the pp65 fusion proteins in infected HFF. Cells were infected at an m.o.i. of 2-3 with the different viruses. Cells were fixed at 2 and 4 d.p.i. and stained with $\mathrm{mAb}$ 65-33. Immunofluorescence analyses were carried out as described in the accompanying article [51]. White bars represent $10 \mu \mathrm{m}$. $\mathbf{c}$ Immunoblot analysis of the amount of fusion protein packaged in the extracellular NIEPs fractions, collected by glyceroltartrate gradient centrifugation [43]. For staining, mAbs 65-33 and 27-287 were used
DB were detectable. Only in the RV-EP0 gradient, a faint smear of DB became apparent. Because bands corresponding to DB were absent in the gradients from RV-VR1, RV-EP1 and RV-EP2 and because the material from the virion fractions was not sufficient for further analysis, only bands from the NIEPs fractions were collected and subjected to immunoblot analyses (Fig. 2c). The pp65-c-myc fusion protein from RV-EP0 appeared to be packaged with similar abundance compared to the wild type pp65 tegument protein. In contrast to that, lower amounts of the fusion proteins from RV-VR1, RV-EP1 and RV-EP2 were detected in the respective NIEPs fractions. These results showed that infection with these three recombinant viruses leads to decreased packaging of the respective pp65-IE1 fusion proteins into viral particles compared to infection with wild type RV-HB5. Taken together, fusion of heterologous partners to the very $\mathrm{C}$-terminus may allow packaging of the fusion protein into NIEPs and virions to various extents, but it may be inappropriate for the generation of recDB.

\section{Ultrastructural analysis of infected cells}

Results obtained by gradient centrifugation and immunoblot analyses suggested that the formation of DB containing the pp65-IE1 fusion proteins was impaired in cells infected with RV-VR1, RV-EP1 or RV-EP2. To corroborate this on the ultrastructural level, electron microscopy was performed as described before [44] on 6-day infected HFF (Fig. 3). Analysis of the nuclei of RV-HB5 infected cells showed electron-dense structures which likely corresponded to the nuclear capsid assembly sites and, in close proximity, the three types of capsids (Fig. 3). In the cytoplasm of RV-HB5 infected HFF, DB and multivesicular bodies (MVB) [45] were present in large numbers. The wild type $\mathrm{DB}$, which were enclosed by a membrane, appeared as round, uniform and electron-dense particles with a size varying between 300 and $500 \mathrm{~nm}$ (white arrows in Fig. 3b). Similar electron-dense structures were found in RV-EP0 infected cells. However they were larger (between $300 \mathrm{~nm}$ and $1 \mu \mathrm{m}$ ) and appeared to be less frequent compared to RV-HB5. Some of the different electron-dense structures were composed of a mixture of capsids, vacuoles and electron-dense masses, and apparently were losing their homogeneity and their shape (grey arrows in Fig. 3c). These cytoplasmic accumulations reached sizes up to $5 \mu \mathrm{m}$. It remains unclear, whether they are related to DB. In contrast to cells infected with RV-HB5 and RV-EP0, cells infected with the other recombinant viruses did not display any formation of DB, although some large electron-dense structures without any specific organisation were observed in the cytoplasm of RV-EP1 and RV-VR1 infected cells 
Fig. 3 Electron micrographs of HFF infected with recombinant viruses. HFF were infected with RV-HB5 (a, b), RV-EP0 (c), RV-EP1 (d), RV-EP2 (e) and RV-VR1 (f) at an m.o.i. of 2-3. Six days after infection, cells were processed for ultrastructural examination as published [44]. Cytoplasmic DB (white arrows); electron dense round aggregates (grey arrows); electron dense aggregates (black arrows); NCA nuclear capsid assembly site; $c y t$ cytoplasm; $n u$ nucleus; $M V B$ multivesicular bodies (composed of virions and DB, and surrounded by a membrane)
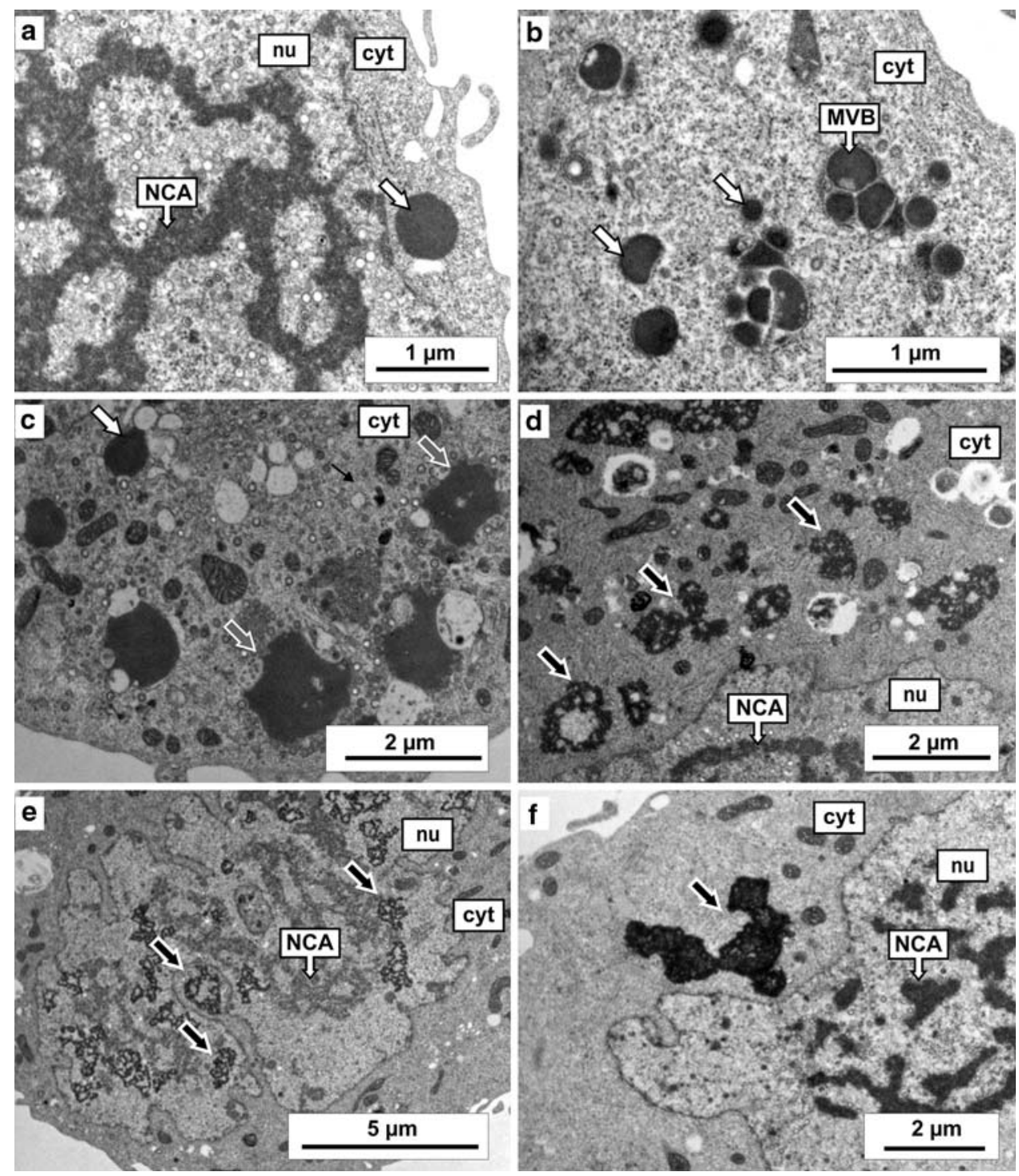

(black arrows in Fig. 3d, f). These aggregates were spread out all over the cytoplasm and reached sizes of up to $7 \mu \mathrm{m}$, whereas the electron-dense accumulations in RV-EP2 infected cells were mainly located in the nuclei (black arrows in Fig. 3e). These analyses confirmed that the minor alteration of adding small peptides to the very $\mathrm{C}$-terminus of pp65 already prevented the formation of DB in the cytoplasm of HFF infected with RV-VR1, RV-EP1 and RV$\mathrm{EP} 2$, but not the production of infectious virions.

Internal seamless fusion of heterologous peptide sequences to the viral pp65 by galK mediated recombineering

The experiments described above provided evidence that fusion of IE1-derived polypeptides to both $\mathrm{C}$ - and $\mathrm{N}$-terminus of pp65 disturbed synthesis of recDB by infected cells. To test, if internal insertion of the heterologous peptide was appropriate to retain DB formation, an alternative technique, employing the bacterial galactokinase $(\mathrm{galK})$ for both positive and negative selection, was used for HCMV BAC recombineering [35]. This method allows precise and seamless modification of the target BAC (Fig. 4). By this, HCMV mutant RV-VM3 was established expressing the IE1 $1_{\mathrm{TMY}}$-myc fusion peptide (as in RV-EP1) at position P548 of pp65 [44].

Immunologic potential of RV-VM3-dense bodies

In a recent paper, we could demonstrate by immunofluorescence analysis that the fusion protein of RV-VM3 behaves like wt pp65 with respect to its subcellular localization in infected HFF. Furthermore, RV-VM3-infected cells release both virions and $\mathrm{DB}$ that contain the fusion protein. The $\mathrm{IE} 1_{\mathrm{TMY}}$ peptide is efficiently presented on the surface of 


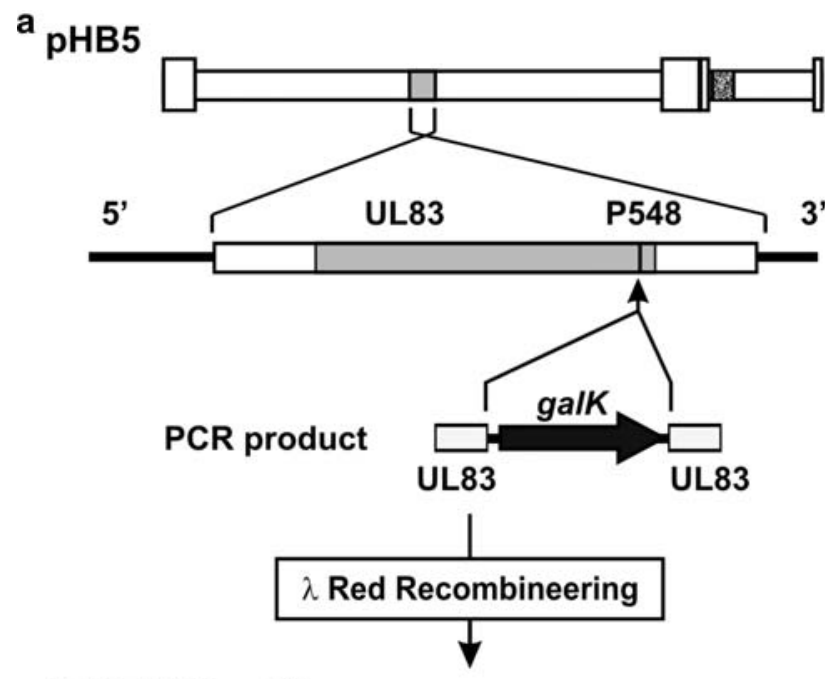

BAC-VM3-galK

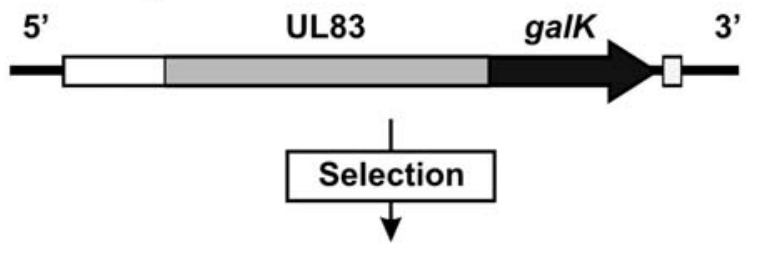

Galactose

b

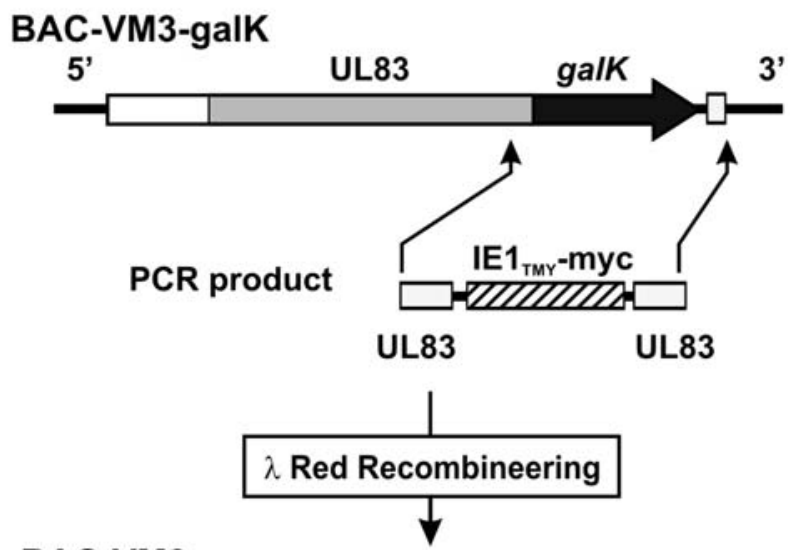

BAC-VM3

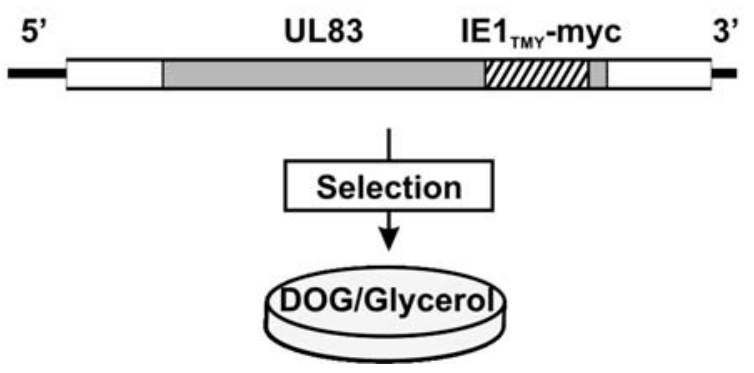

cells exposed to the recombinant particles [44]. However, one critical question remained open, namely whether an immune response against the recombinant antigen could be
Fig. 4 Genetic modification of HCMV BACs by using galK-mediated positive/negative selection. a Structure of the PCR-product used for insertion of the galK-gene into position P548 of pp65 of BAC pHB5, using $\lambda$-Red-recombineering in E. coli strain SW102, and structure of the intermediate BAC clone BAC-VM3-galK. Proline 548 (P548) was chosen for targeting, as this location had been successfully used before to generate recombinant DB [31]. Bacteria harbouring this BAC-VM3galK were selected by supplying galactose as carbon source. b structure of the PCR fragment containing IE1 $1_{\mathrm{TMY}}$-myc (as in RV-EP1), used to replace the galK gene, and structure of the final construct BACVM3. Primers for amplification have been published elsewhere [44]. BAC-VM3 was isolated by adding 2-deoxygalactose (DOG) for negative selection of galK expression and glycerol. Recombinant virus RVVM3 was reconstituted by transfecting BAC-VM3 into HFF [44]

mounted after immunization with DB from RV-VM3 (DB-VM3).

To test this, 10-12-week-old HLA-A2 transgenic mice (HHD mice) [46] were immunized once intraperitoneally with $6 \mu \mathrm{g}$ DB from RV-HB5 (wt-DB) or DB-VM3, or with PBS as negative control. Lymphocytes were prepared from the spleens at day 7 after immunization and were cultured for two successive rounds of weekly restimulation in medium containing IL-2 and the specific peptide. The cells were subjected to an IFN- $\gamma$ ELISpot analysis after the first and second restimulation, using peptide loaded RMA-S HHD stimulator cells $[46,47]$. CD3\&-redirected ELISpot-analysis [48] was used to determine the total number of cells in the effector cell population that were able to respond with IFN $-\gamma$ secretion (data not shown). The percentage of peptide specific CD8 T cells was calculated in the overall responding $\mathrm{T}$ cell population. Spleen cells from animals that were exposed to wt-DB or DB-VM3 were significantly stimulated with pp65 $\mathrm{NLV}$ (Fig. 5a). Stimulation of cells from DB immunized mice with IE1 $1_{\mathrm{TMY}}$ did not result in significant expansion of IE1-specific $\mathrm{T}$ cells. This was an expected result, as DB do not contain IE1. In contrast, splenocytes from animals injected with DBVM3 were stimulated by the IE $1_{\mathrm{TMY}}$ to about $60 \%$ of the total inducible population after 1 week and reached $100 \%$ after 2 weeks (Fig. 5b). These results provided the first proof that a heterologous antigenic determinant, not naturally present in DB, can prime a CD8 $\mathrm{T}$ cell response if expressed in fusion with pp65 and packaged into recDB.

\section{Discussion}

In this communication, we have described experiments aiming at the modification of the protein composition of HCMV DB by fusing portions of a heterologous protein to pp65. Whilst the expression of $\mathrm{N}$ - and C-terminal pp65 fusion proteins in cells infected with the respective HCMV mutant viruses did not result in the release of significant numbers of recDB, the results obtained may well extend 


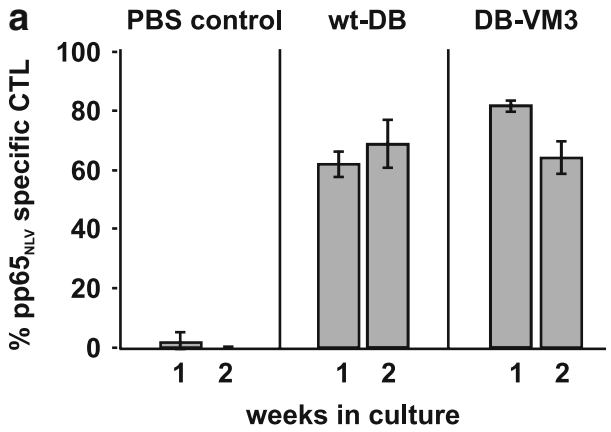

Fig. 5 ELISpot-analysis of CD8 T cells from DB-immunized HLAA2 transgenic HHD mice. Ten to twelve-week-old HLA-A2 transgenic HHD mice [46] were immunized intraperitoneally (i.p.) with $6 \mu \mathrm{g}$ of purified DB of RV-HB5 (wt-DB) or of RV-VM3 (DB-VM3). Five animals were included in each group. PBS was applied to a control group. One week after immunization, spleen cells were prepared and restimulated with $10^{-9} \mathrm{M}$ of either pp $65_{\mathrm{NLV}}$ or IE $1_{\mathrm{TMY}}$ peptide in the presence of $0.2 \mathrm{ng} / \mathrm{ml} \mathrm{IL2}$. Cells were cultured for 1 week. A fraction of the cells

our understanding of the biology of pp65 and of HCMV particle morphogenesis.

Fusion of a heterologous polypeptide following the first ATG codon downstream of the transcription initiation site of the pp65 gene, as defined by Rüger et al. [42], led to a complete abrogation of pp65 protein expression in RV-SR1 infected cells. The reason for the lack of expression is unclear at the current stage. Depto and Stenberg [49] reported that, in transient transfection analyses, the octamer sequence ATTTCGGG found at position -51 with respect to the proposed transcription start site of the pp65 gene was essential for promoter activation. They identified the same sequence at position +93 and an inverted version at +67 . There was no analysis performed on the relevance of these downstream sequences with respect to activation of the pp65 promoter. Both sequences were translocated, however, to a far downstream position by constructing the fusion gene in RV-SR1 (Fig. 1). Consequently, disrupting the downstream promoter structure could interfere with the expression of the N-terminal fusion protein. Alternatively, there may be additional transcription start sites downstream of position +93 that could be more important than the one described before [42].

The fusion proteins, with the exception of that of RVEP2, were packaged into NIEPs. However, extracellular DB were, if at all, detectable only after infection with RVEP0. From these analyses, it can be concluded that the formation of at least NIEPs containing pp65 fusion proteins was unaffected in RV-VR1-, RV-EP0-, and RV-EP1infected cells. It may be assumed that also virion formation was unimpaired, although formal analyses still have to be performed to prove this. No DB formation, as compared with wt-infected cells, became apparent on the ultrastructural level. In accordance, cells infected with a pp65 negative

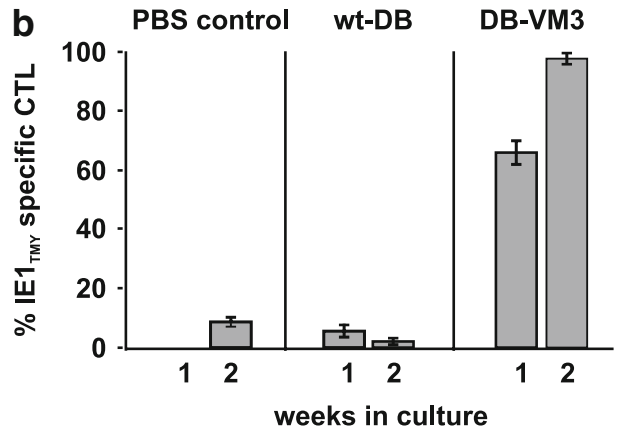

was then subjected to an IFN- $\gamma$ ELISpot analysis [44] using $10^{5}$ RMA$\mathrm{S}$ HHD cells as stimulators loaded with $10^{-9} \mathrm{M}$ pp $65_{\mathrm{NLV}}$ or IE $1_{\mathrm{TMY}}$, respectively. The remaining cells were restimulated once again, cultured for another week and then subjected to another IFN- $\gamma$ ELISpot analysis. a ELISpot-analysis of pp $65_{\mathrm{NLV}^{-}}$-specific CTLs. b ELISpotanalysis of $\mathrm{IE}_{\mathrm{TMY}}$-specific CTLs. The percentage of peptide specific CD8 $\mathrm{T}$ cells was calculated in the overall reactive effector cell population determined by polyclonal stimulation via CD3 $\varepsilon$ [48]

virus released virions and NIEPs, but no DB [50]. These results point towards a dichotomy in the ability of infected cells to package the pp65 fusion protein into DB and NIEPs. In contrast to the current understanding, this may indicate that formation and maybe also release of DB and NIEPs (or virions) follow separate pathways.

The fusion protein expressed by RV-EP2 was found in low amounts in extracellular NIEPs, although its expression level was indistinguishable from that of the fusion proteins of the other viruses. As a striking difference, the RV-EP2 fusion protein remained mainly in the nucleus at late times p.i.. Consequently, the defect of packaging of this protein in progeny particles seems to be related to an impaired nuclear export of this polypeptide. This cannot be explained by differences in size or position of the IE1-peptide fused to pp65, as both were identical for RV-EP1 and RV-EP2. Alternatively, the primary structure of the protein fused to the very C-terminus of pp65 may influence nuclear export and, as a consequence, packaging of the recombinant protein into viral particles. Further work has to be conducted to investigate this issue.

The work described in this article was experimental in nature to identify insertion sites within pp65, optimal for formation and release of recDB. However, it was not designed to procure a final vaccine candidate to be used in humans. For a final formulation, inclusion of undesired sequences like myc-tags or FRT-sites should be avoided. Using the positive selection procedure of BAC modification in combination with FLP-mediated excision will always leave behind operational traces, such as FRT-sites close to the insertion site. In contrast, employing galK for both positive and negative selection allows precise and seamless modification of the HCMV strain used for vaccine production and thus may be preferentially used to generate recDB. 
The antigens, however, that should be included in such a recDB vaccine to provide a sufficient breadth of the immune response still need to be defined. For this, the diversity of human MHC class I haplotypes and of the antiviral CD8 $\mathrm{T}$ cell responses have to be considered. We could show here for the first time, yet, that recDB can prime a $\mathrm{CD} 8 \mathrm{~T}$ cell response against an HLA-A2 presented model peptide, not normally contained in DB. Significant numbers of IE1-specific CD8 $\mathrm{T}$ cells could be detected after one or two rounds of in vitro restimulation, whereas the ex vivo frequency of these cells was very low (data not shown). Nevertheless, even very low numbers of ex vivo isolated IE1-specific CD8 T cellsnamely 400 cells-are sufficient to effectively control CMV infection, as has been shown in the murine CMV infection model [15]. In conclusion, the results of these initial immunization experiments are encouraging. However, further studies with the aim to refine the strategy of stimulating an HCMV specific T lymphocyte response, including serial immunizations and the use of adjuvant, need to be conducted.

\section{Outlook}

Development of vaccines against human herpesviruses has proven to be a formidable endeavour. A wisdom that was accomplished in this process is that complex problems may not be successfully met by simple solutions. Translating this into biology means that complex infections, like that with herpesviruses, may not be successfully addressed with vaccines relying on single antigens. More elaborate formulations are needed to confer reliable protection. In the case of HCMV, DB may be a basis to achieve this noble goal of preventing disease by a vaccine. Recent implementation of recombineering methods to genetically engineer the HCMV genome in bacteria provides the opportunity to optimise the antigenic content of these particles. Different recDB can then be tested in vitro, e.g. for their capacity to stimulate human HCMV specific $T$ cells. These approaches will help to finally establish a candidate vaccine. Such a vaccine may then be tested for its immunoprophylactic potential in combination with the adoptive transfer of TCR-sorted antiviral T lymphocytes. This strategy will preferentially be explored in murine challenge models and subsequently be investigated for its benefit on the level of clinical studies in HSCT patients.

Acknowledgments The technical assistance of Manuela Starke and Elisabeth Sehn is gratefully acknowledged. We are indebted to Martin Messerle, Eva Borst, and Ulrich Koszinowski for HCMV BAC pHB5, to Neil Copeland for bacterial strains SW102 and EL250 and for
pgalK, to François Lemonnier for the transgenic mouse strain HHD and RMA-S HHD cells, to Michael Mach for plasmid pCP-o-15-link2 and to William Britt for monoclonal antibodies. This work was supported by grants from the Deutsche Forschungsgemeinschaft, DFG Research Training Program 1043 "Antigen-Specific Immunotherapy" (V.M., S.R., and B.P.), SFB 490, individual projects E7 (B.P.) and E3 (V.B., P.D. and R.H.), and DFG-individual project Wo548-6 (U.W.).

\section{References}

1. Hebart H, Einsele H (2004) Clinical aspects of CMV infection after stem cell transplantation. Hum Immunol 65:432-436

2. Fowler KB, Boppana SB (2006) Congenital cytomegalovirus (CMV) infection and hearing deficit. J Clin Virol 35:226-231

3. Mocarski ES, Shenk T, Pass RF (2007) Cytomegaloviruses. In: Knipe DM, Howley PM (eds) Fields virology. Lippincott Williams \& Wilkins, Philadelphia, pp 2701-2772

4. van der Sande MA, Kaye S, Miles DJ, Waight P, Jeffries DJ, Ojuola OO, Palmero M, Pinder M, Ismaili J, Flanagan KL, Aveika AA, Zaman A, Rowland-Jones S, McConkey SJ, Whittle HC, Marchant A (2007) Risk factors for and clinical outcome of congenital cytomegalovirus infection in a peri-urban West-African birth cohort. PLoS ONE 2:e492

5. Reddehase MJ, Mutter W, Münch K, Bühring HJ, Koszinowski UH (1987) CD8-positive T lymphocytes specific for murine cytomegalovirus immediate-early antigens mediate protective immunity. J Virol 61:3102-3108

6. Steffens HP, Kurz S, Holtappels R, Reddehase MJ (1998) Preemptive CD8 T-cell immunotherapy of acute cytomegalovirus infection prevents lethal disease, limits the burden of latent viral genomes, and reduces the risk of virus recurrence. J Virol 72:1797-1804

7. Walter EA, Greenberg PD, Gilbert MJ, Finch RJ, Watanabe KS, Thomas ED, Riddell SR (1995) Reconstitution of cellular immunity against cytomegalovirus in recipients of allogeneic bone marrow by transfer of T-cell clones from the donor. N Engl J Med 333:1038-1044

8. Einsele H, Roosnek E, Rufer N, Sinzger C, Riegler S, Loffler J, Grigoleit U, Moris A, Rammensee HG, Kanz L, Kleihauer A, Frank F, Jahn G, Hebart H (2002) Infusion of cytomegalovirus (CMV)-specific T cells for the treatment of CMV infection not responding to antiviral chemotherapy. Blood 99:3916-3922

9. Peggs KS, Verfuerth S, Pizzey A, Khan N, Guiver M, Moss PA, Mackinnon S (2003) Adoptive cellular therapy for early cytomegalovirus infection after allogeneic stem-cell transplantation with virus-specific T-cell lines. Lancet 362:1375-1377

10. Cobbold M, Khan N, Pourgheysari B, Tauro S, McDonald D, Osman H, Assenmacher M, Billingham L, Steward C, Crawley C, Olavarria E, Goldman J, Chakraverty R, Mahendra P, Craddock C, Moss PA (2005) Adoptive transfer of cytomegalovirus-specific CTL to stem cell transplant patients after selection by HLA-peptide tetramers. J Exp Med 202:379-386

11. Moss P, Rickinson A (2005) Cellular immunotherapy for viral infection after HSC transplantation. Nat Rev Immunol 5:9-20

12. Craddock C, Szydlo RM, Dazzi F, Olavarria E, Cwynarski K, Yong A, Brookes P, de la FJ, Kanfer E, Apperley JF, Goldman JM (2001) Cytomegalovirus seropositivity adversely influences outcome after T-depleted unrelated donor transplant in patients with chronic myeloid leukaemia: the case for tailored graft-versus-host disease prophylaxis. Br J Haematol 112:228-236

13. Wehler TC, Nonn M, Brandt B, Britten CM, Grone M, Todorova M, Link I, Khan SA, Meyer RG, Huber C, Hartwig UF, Herr W (2007) Targeting the activation-induced antigen CD137 can selectively deplete alloreactive $\mathrm{T}$ cells from antileukemic and antitumor donor T-cell lines. Blood 109:365-373 
14. Hartwig UF, Nonn M, Khan S, Link I, Huber C, Herr W (2008) Depletion of alloreactive donor T lymphocytes by CD95-mediated activation-induced cell death retains antileukemic, antiviral, and immunoregulatory $\mathrm{T}$ cell immunity. Biol Blood Marrow Transplant 14:99-109

15. Pahl-Seibert MF, Jülch M, Podlech J, Thomas D, Deegen P, Reddehase MJ, Holtappels R (2005) Highly protective in vivo function of cytomegalovirus IE1 epitope-specific memory CD8 T cells purified by T-cell receptor-based cell sorting. J Virol 79:54005413

16. Holtappels R, Podlech J, Pahl-Seibert MF, Jülch M, Thomas D, Simon CO, Wagner M, Reddehase MJ (2004) Cytomegalovirus misleads its host by priming of CD8 T cells specific for an epitope not presented in infected tissues. J Exp Med 199:131-136

17. Khanna R, Diamond DJ (2006) Human cytomegalovirus vaccine: time to look for alternative options. Trends Mol Med 12:26-33

18. Schleiss MR, Heineman TC (2005) Progress toward an elusive goal: current status of cytomegalovirus vaccines. Expert Rev Vaccines 4:381-406

19. Pepperl-Klindworth S, Plachter B (2006) Current perspectives in vaccine development. In: Reddehase MJ (eds) Cytomegaloviruses: molecular biology and immunology. Caister Academic Press Ltd, Wymondham

20. Zhong J, Khanna R (2007) Vaccine strategies against human cytomegalovirus infection. Expert Rev Anti Infect Ther 5:449-459

21. Pepperl S, Münster J, Mach M, Harris JR, Plachter B (2000) Dense bodies of human cytomegalovirus induce both humoral and cellular immune responses in the absence of viral gene expression. J Virol 74:6132-6146

22. Pepperl-Klindworth S, Frankenberg N, Plachter B (2002) Development of novel vaccine strategies against human cytomegalovirus infection based on subviral particles. J Clin Virol 25 (Suppl 2):S75-S85

23. Beninga J, Kropff B, Mach M (1995) Comparative analysis of fourteen individual human cytomegalovirus proteins for helper $\mathrm{T}$ cell response. J Gen Virol 76:153-160

24. Wills MR, Carmichael AJ, Mynard K, Jin X, Weekes MP, Plachter B, Sissons JG (1996) The human cytotoxic T-lymphocyte (CTL) response to cytomegalovirus is dominated by structural protein pp65: frequency, specificity, and T-cell receptor usage of pp65specific CTL. J Virol 70:7569-7579

25. McLaughlin-Taylor E, Pande H, Forman SJ, Tanamachi B, Li CR, Zaia JA, Greenberg PD, Riddell SR (1994) Identification of the major late human cytomegalovirus matrix protein pp65 as a target antigen for CD8+ virus-specific cytotoxic T lymphocytes. J Med Virol 43:103-110

26. Borysiewicz LK, Hickling JK, Graham S, Sinclair J, Cranage MP, Smith GL, Sissons JG (1988) Human cytomegalovirus-specific cytotoxic T cells. Relative frequency of stage-specific CTL recognizing the $72-\mathrm{kD}$ immediate early protein and glycoprotein B expressed by recombinant vaccinia viruses. J Exp Med 168:919-931

27. Kern F, Surel IP, Faulhaber N, Frömmel C, Schneider-Mergener J, Schonemann C, Reinke P, Volk HD (1999) Target structures of the CD8(+)-T-cell response to human cytomegalovirus: the 72-kilodalton major immediate-early protein revisited. J Virol 73:81798184

28. Bunde T, Kirchner A, Hoffmeister B, Habedank D, Hetzer R, Cherepnev G, Proesch S, Reinke P, Volk HD, Lehmkuhl H, Kern F (2005) Protection from cytomegalovirus after transplantation is correlated with immediate early 1-specific CD8 T cells. J Exp Med 201:1031-1036

29. Lacey SF, La RC, Zhou W, Sharma MC, Martinez J, Krishnan A, Gallez-Hawkins G, Thao L, Longmate J, Spielberger R, Forman SJ, Limaye A, Zaia JA, Diamond DJ (2006) Functional comparison of $\mathrm{T}$ cells recognizing cytomegalovirus pp65 and intermediate-early antigen polypeptides in hematopoietic stem-cell transplant and solid organ transplant recipients. J Infect Dis 194:1410-1421

30. Simon CO, Holtappels R, Tervo HM, Böhm V, Däubner T, Oehrlein-Karpi SA, Kühnapfel B, Renzaho A, Strand D, Podlech J, Reddehase MJ, Grzimek NKA (2006) CD8 T cells control cytomegalovirus latency by epitope-specific sensing of transcriptional reactivation. J Virol 80:10436-10456

31. Pepperl-Klindworth S, Frankenberg N, Riegler S, Plachter B (2003) Protein delivery by subviral particles of human cytomegalovirus. Gene Ther 10:278-284

32. Messerle M, Crnkovic I, Hammerschmidt W, Ziegler H, Koszinowski UH (1997) Cloning and mutagenesis of a herpesvirus genome as an infectious bacterial artificial chromosome. Proc Natl Acad Sci USA 94:14759-14763

33. Borst EM, Hahn G, Koszinowski UH, Messerle M (1999) Cloning of the human cytomegalovirus (HCMV) genome as an infectious bacterial artificial chromosome in Escherichia coli: a new approach for construction of HCMV mutants. J Virol 73:8320-8329

34. Lee EC, Yu D, Martinez d V, Tessarollo L, Swing DA, Court DL, Jenkins NA, Copeland NG (2001) A highly efficient Escherichia coli-based chromosome engineering system adapted for recombinogenic targeting and subcloning of BAC DNA. Genomics 73:5665

35. Warming S, Costantino N, Court DL, Jenkins NA, Copeland NG (2005) Simple and highly efficient BAC recombineering using galK selection. Nucleic Acids Res 33:e36

36. Mach M, Kropff B, Kryzaniak M, Britt W (2005) Complex formation by glycoproteins $\mathrm{M}$ and $\mathrm{N}$ of human cytomegalovirus: structural and functional aspects. J Virol 79:2160-2170

37. Greenaway PJ, Oram JD, Downing RG, Patel K (1982) Human cytomegalovirus DNA: BamHI, EcoRI and PstI restriction endonuclease cleavage maps. Gene 18:355-360

38. Gallez-Hawkins G, Villacres MC, Li X, Sanborn MC, Lomeli NA, Zaia JA (2003) Use of transgenic HLA A*0201/Kb and HHD II mice to evaluate frequency of cytomegalovirus IE1-derived peptide usage in eliciting human CD8 cytokine response. J Virol 77:4457-4462

39. Retiere C, Prod'homme V, Imbert-Marcille BM, Bonneville M, Vie H, Hallet MM (2000) Generation of cytomegalovirus-specific human T-lymphocyte clones by using autologous B-lymphoblastoid cells with stable expression of pp65 or IE1 proteins: a tool to study the fine specificity of the antiviral response. J Virol 74:39483952

40. Prod'homme V, Retiere C, Imbert-Marcille BM, Bonneville M, Hallet MM (2003) Modulation of HLA-A*0201-restricted T cell responses by natural polymorphism in the IE1(315-324) epitope of human cytomegalovirus. J Immunol 170:2030-2036

41. Frankenberg N, Pepperl-Klindworth S, Meyer RG, Plachter B (2002) Identification of a conserved HLA-A2-restricted decapeptide from the IE1 protein (pUL123) of human cytomegalovirus. Virology 295:208-216

42. Rüger B, Klages S, Walla B, Albrecht J, Fleckenstein B, Tomlinson P, Barrell B (1987) Primary structure and transcription of the genes coding for the two virion phosphoproteins pp65 and pp71 of human cytomegalovirus. J Virol 61:446-453

43. Irmiere A, Gibson W (1983) Isolation and characterization of a noninfectious virion-like particle released from cells infected with human strains of cytomegalovirus. Virology 130:118-133

44. Mersseman V, Besold K, Reddehase MJ, Wolfrum U, Strand D, Plachter B, Reyda S (2008) Exogenous introduction of an immunodominant peptide from the non-structural IE1 protein of human cytomegalovirus into the MHC class I presentation pathway by recombinant dense bodies. J Gen Virol 89:369-379

45. Gilloteaux J, Nassiri MR (2000) Human bone marrow fibroblasts infected by cytomegalovirus: ultrastructural observations. J Submicrosc Cytol Pathol 32:17-45 
46. Pascolo S, Bervas N, Ure JM, Smith AG, Lemonnier FA, Perarnau B (1997) HLA-A2.1-restricted education and cytolytic activity of CD8(+) T lymphocytes from beta2 microglobulin (beta2m) HLAA2.1 monochain transgenic $\mathrm{H}-2 \mathrm{Db}$ beta2m double knockout mice. J Exp Med 185:2043-2051

47. Loirat D, Lemonnier FA, Michel ML (2000) Multiepitopic HLAA*0201-restricted immune response against hepatitis B surface antigen after DNA-based immunization. J Immunol 165:47484755

48. Holtappels R, Pahl-Seibert MF, Thomas D, Reddehase MJ (2000) Enrichment of immediate-early 1 (m123/pp89) peptide-specific CD8 T cells in a pulmonary CD62L(lo) memory-effector cell pool during latent murine cytomegalovirus infection of the lungs. J Virol 74:11495-11503

49. Depto AS, Stenberg RM (1989) Regulated expression of the human cytomegalovirus pp65 gene: octamer sequence in the promoter is required for activation by viral gene products. J Virol 63:1232-1238

50. Schmolke S, Kern HF, Drescher P, Jahn G, Plachter B (1995) The dominant phosphoprotein pp65 (UL83) of human cytomegalovirus is dispensable for growth in cell culture. J Virol 69:5959-5968

51. Besold K, Plachter B (2008) Recombinant viruses as tools to study human cytomegalovirus immune evasion. Med Microbiol Immunol (in press) 